\title{
The Sulphidation Properties of Pre-oxidized Yttrium-ion-implanted Incoloy 800H*
}

\author{
E. A. POLMAN, T. FRANSEN and P. J. GELLINGS \\ Laboratory for Inorganic Chemistry and Materials Science, Twente University of Technology, 7500 AE Enschede \\ (The Netherlands)
}

(Received May 30, 1986; in revised form July 11, 1986)

\section{ABSTRACT}

On sulphidation of pre-oxidized yttriumimplanted Incoloy $800 \mathrm{H}$ an improvement in sulphidation resistance is obtained. Preoxidized krypton-implanted alloy and aluminium-implanted alloy have sulphidation rates which are about the same as that of non-implanted pre-oxidized Incoloy $800 \mathrm{H}$. Scanning electron microscopy observations show that one of the effects of yttrium implantation is to decrease the corrosion rate at the alloy grain boundaries.

\section{INTRODUCTION}

The influence of ion implantation on the oxidation of various metals and alloys has frequently been reported. In particular, Bennett et al. [1-3] and Pivin et al. [4] have shown that implantation of yttrium or cerium leads to an improved oxidation resistance of $\mathrm{Cr}_{2} \mathrm{O}_{3}$-forming alloys. Implantation of aluminium ions and noble gas ions has been found to result in little or no beneficial effect $[1,5]$. The improved oxidation resistance of yttrium-implanted alloys is often attributed to a reduction in the outward diffusion of substrate metal ions.

Little attention has been paid to the influence of implantation on sulphidation. Recently a beneficial effect of yttrium implantation in Incoloy $800 \mathrm{H}$ if an oxidizing pretreatment was applied was reported [6].

In this paper the effect of ion implantation is reported more extensively for several con-

\footnotetext{
*Paper presented at the International Symposium on High Temperature Corrosion, Université de Provence, Marseille 13331, France, July 7-11, 1986.
}

ditions. The influence of yttrium on the composition and the structure of the protective oxide scale is also a main subject of this paper.

\section{EXPERIMENTAL DETAILS}

Incoloy $800 \mathrm{H}$ was received as bar material and contained the following main components: $45 \mathrm{wt} . \% \mathrm{Fe}, 20 \mathrm{wt} . \% \mathrm{Cr}, 32 \mathrm{wt} . \% \mathrm{Ni}, 1 \mathrm{wt} . \% \mathrm{Mn}$ and $0.4 \mathrm{wt} . \% \mathrm{Ti}$. After heat treatment at 1100 and $950^{\circ} \mathrm{C}$, followed by quenching in water, cylindrical samples were machined (diameter $5 \mathrm{~mm}$; length, $20 \mathrm{~mm}$ ). These were then ground on emery paper (600 grit) and polished with diamond paste (final pass, $1 \mu \mathrm{m}$ ) and $\mathrm{Al}_{2} \mathrm{O}_{3}(0.05 \mu \mathrm{m})$. Finally, they were cleaned ultrasonically in ethanol.

All sides of the cylindrical specimens were implanted using the $110 \mathrm{keV}$ implantation facility at the University of Groningen with $\mathrm{Y}_{2} \mathrm{O}_{3}$ plus $\mathrm{CCl}_{4}$ as the starting material. In order to implant the cylindrical side homogeneously, the specimens were rotated. The implanted dose was $10^{16} \mathrm{Y}^{+} \mathrm{cm}^{-2}$. The yttrium distribution in the implanted pre-oxidized samples was investigated by means of Rutherford backscattering at the University of Groningen. Scanning electron microscopy (SEM) observations and energy-dispersive Xray analyses of the oxide and sulphide scales were performed on a JEOL JSM-35CF instrument. By means of X-ray diffraction the phase composition of the oxide scales was investigated. Thermogravimetric measurements were performed using a Cahn-1000 electrical thermobalance.

Sulphidation tests were carried out in two different atmospheres. At $640^{\circ} \mathrm{C}$, argon flowing at a rate of $11 \mathrm{l} \mathrm{h}^{-1}$ was bubbled through water at $15.0^{\circ} \mathrm{C}$ and mixed with a gas consist- 
ing of $95 \% \mathrm{H}_{2}$ and $5 \% \mathrm{H}_{2} \mathrm{~S}$ flowing at a rate of $31 \mathrm{~h}^{-1}$. In this atmosphere, $P_{\mathrm{S}_{2}}=1.7 \mathrm{X}$ $10^{-8}$ atm and $P_{\mathrm{O}_{2}}=8.5 \times 10^{-26}$ atm. Other sulphidation tests were performed at $560^{\circ} \mathrm{C}$ in a gas mixture of $78.3 \% \mathrm{Ar}, 20.6 \% \mathrm{H}_{2}$ and $1 \% \mathrm{H}_{2} \mathrm{~S}$ and containing approximately 100 ppm $\mathrm{O}_{2}$ as an impurity for which the calculated partial pressure values were $P_{\mathrm{S}_{2}}=1.8 \mathrm{X}$ $10^{-9} \mathrm{~atm}$ and $P_{\mathrm{O}_{2}}=10^{-32} \mathrm{~atm}$.

\section{RESULTS}

\subsection{Oxidation tests}

Before thermogravimetric sulphidation tests were carried out, an oxidizing pretreatment was applied. To compare the sulphidation resistance of unimplanted cylindrical samples, the oxide thickness should be the same.

On oxidation (in $\mathrm{O}_{2}$ at $1020^{\circ} \mathrm{C}$ ) of rectangular $10 \mathrm{~mm} \times 8 \mathrm{~mm} \times 3 \mathrm{~mm}$ samples which had been implanted with a dose of $10^{16} \mathrm{Y}^{+} \mathrm{cm}^{-2}$, a reduction in the oxidation rate was observed. The oxidation kinetics are shown in Fig. 1. The reduction in oxidation rate by $45 \%$ for implanted samples is in agreement with the values found by Pivin et al. [4] and Bennett et al. [3] for yttrium-implanted $\mathrm{Cr}_{2} \mathrm{O}_{3}$-forming alloys.

Before sulphidation was carried out, unimplanted samples were oxidized for $3 \mathrm{~h}$ at

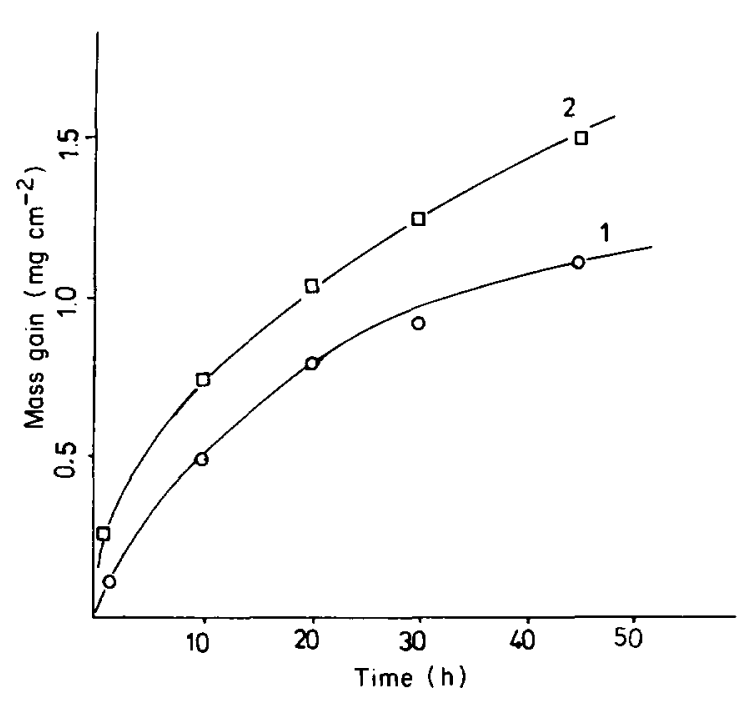

Fig. 1. Thermogravimetric results for Incoloy $800 \mathrm{H}$ in an $\mathrm{O}_{2}$ atmosphere at $1020^{\circ} \mathrm{C}$ : curve 1 , implanted $\left(10^{16} \mathrm{Y}^{+.} \mathrm{cm}^{-2}\right)$ sample; curve 2 , unimplanted sample. $960^{\circ} \mathrm{C}$ and yttrium-implanted specimens were oxidized for $3 \mathrm{~h}$ at $1020^{\circ} \mathrm{C}$. On preoxidation, both aluminium-implanted samples and krypton-implanted samples showed no reduction in oxidation rate. For all samples a scale thickness of $1.4 \mu \mathrm{m}$ was obtained.

The absence of a change in oxidation kinetics for aluminium-implanted and kryptonimplanted alloys agrees with the results of the previous experiments of Antill et al. [5] and Bennett et al. [1].

\subsection{Sulphidation tests}

The sulphidation of non-pre-oxidized yttrium-implanted samples does not result in a decrease in the sulphidation rate. However, if an oxidizing pretreatment is applied, the reduction in sulphidation rate for yttrium-implanted Incoloy $800 \mathrm{H}$ is about $70 \%$ after $50 \mathrm{~h}$ at $560^{\circ} \mathrm{C}$ and at $P_{\mathrm{O}_{2}}=10^{-32}$ atm and $P_{\mathrm{S}_{2}}=1.8 \times 10^{-9}$ atm. Aluminiumimplanted pre-oxidized samples show no beneficial effect under these sulphidation conditions (Fig. 2). Krypton-implanted preoxidized samples have a sulphidation rate about the same as that of unimplanted samples except for a small deviation at the beginning.

Yttrium-implanted pre-oxidized samples, sulphidized at $P_{\mathrm{O}_{2}}=8.5 \times 10^{-26}$ atm and $P_{\mathrm{S}_{2}}=1.7 \times 10^{-8} \mathrm{~atm}$, show complete protec-

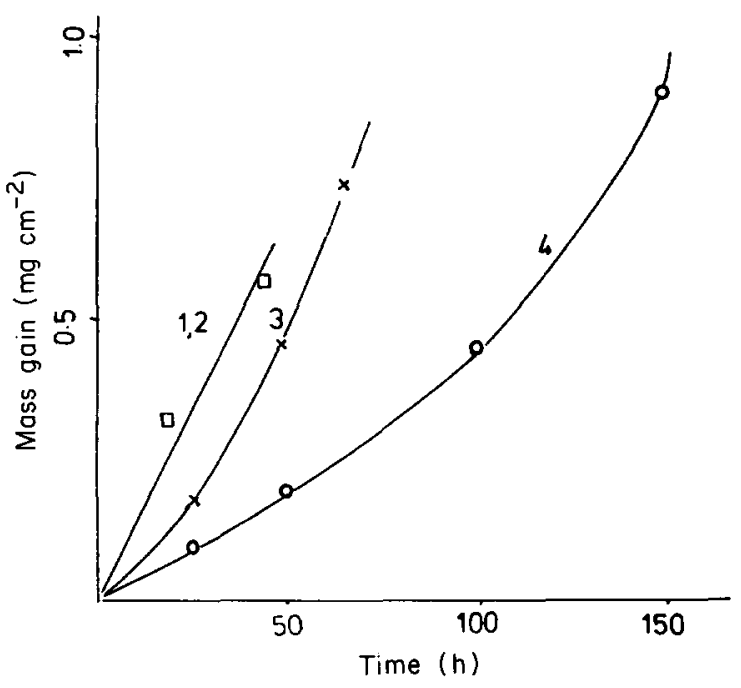

Fig. 2. Sulphidation at $560^{\circ} \mathrm{C}$ in $\mathrm{H}_{2}-\mathrm{H}_{2} \mathrm{~S}$ : curve 1 , unimplanted sample; curve 2 , aluminium-implanted sample; curve 3 , krypton-implanted sample; curve 4 , yttrium-implanted sample. 
tion for $25 \mathrm{~h}$. The reduction in sulphidation rate is $95 \%$ for yttrium-implanted pre-oxidized samples after $50 \mathrm{~h}$ (Fig. 3).

\subsection{Rutherford backscattering}

Rutherford backscattering was applied to measure the yttrium distribution in the protective oxide scale. Before pre-oxidation the sample was implanted at a dose of $10^{16} \mathrm{Y}^{+}$ $\mathrm{cm}^{-2}$ and the oxide scale thickness after preoxidation was about $0.5 \mu \mathrm{m}$. The yttrium distribution after pre-oxidation is shown in Fig. 4. The yttrium in the oxide scale is concentrated near the oxide-gas interface. This

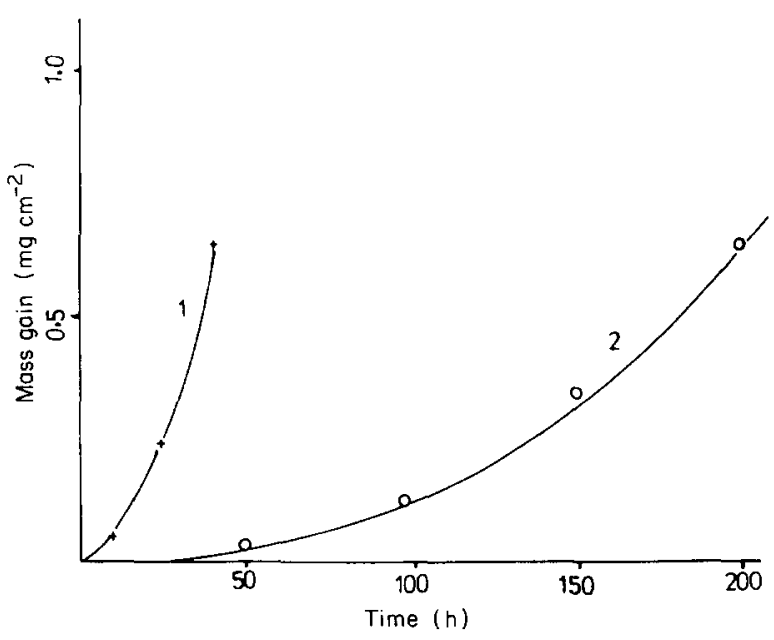

Fig. 3. Sulphidation at $640^{\circ} \mathrm{C}$ in $\mathrm{H}_{2}-\mathrm{H}_{2} \mathrm{~S}-\mathrm{H}_{2} \mathrm{O}$ : curve 1 , unimplanted sample; curve 2 , yttriumimplanted sample.

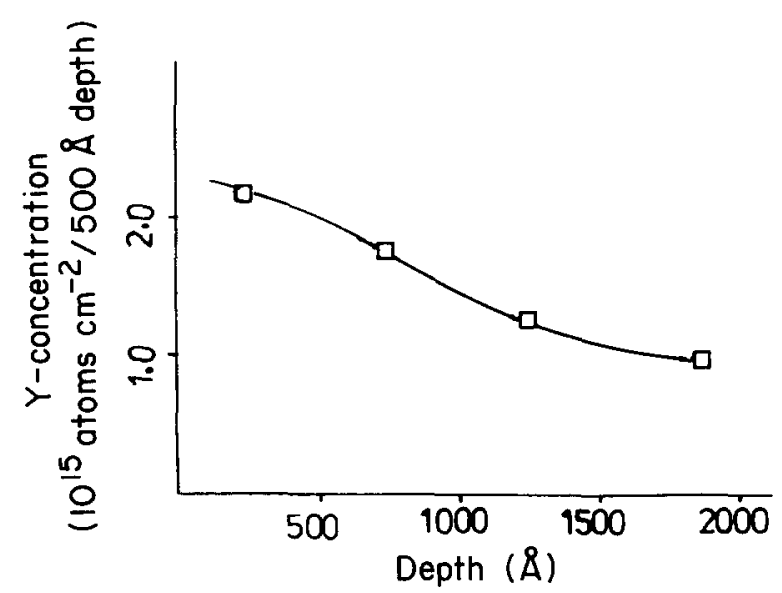

Fig. 4. Yttrium depth profile in pre-oxidized Incoloy $800 \mathrm{H}$. result is in agreement with the results of Bennett et al., who investigated yttrium and cerium distributions in oxide scales of implanted 20 wt.\% $\mathrm{Cr}-25 \mathrm{wt} . \%$ Ni niobiumstabilized alloys [3]. Bennett et al. concluded that most of the yttrium, implanted at a total dose of $10^{17} \mathrm{Y}^{+} \mathrm{cm}^{-2}$, remains in the outer $1000 \AA$ for oxide scales up to $0.5 \mu \mathrm{m}$.

\subsection{X-ray diffraction measurements}

Changes in the scale composition were studied by means of X-ray diffraction. The ratios of the amount of spinel phase to the amount of $\mathrm{Cr}_{2} \mathrm{O}_{3}$ phase were measured by comparing the intensity of the spinel (311) reflection and the $\mathrm{Cr}_{2} \mathrm{O}_{3}$ (104) reflection. The exact spinel phase composition was not determined. Energy-dispersive X-ray analysis indicates that chromium and manganese are the main components in the spinel phase. Nickel and iron are probably also present in the spinel phase. Both the unimplanted and the yttrium-implanted specimens had an oxide scale thickness of $1.4 \mu \mathrm{m}$ (Table 1 ). Although the intensity ratios cannot be strictly interpreted as molar ratios, the result shows that the amount of spinel phase in the oxide scale is increased because of yttrium implantation. This change in oxide phase ratios for $\mathrm{Cr}_{2} \mathrm{O}_{3}$-forming alloys due to yttrium ion implantation has also been observed by Bennett et al. [3].

\subsection{Scanning electron microscopy observa- tions}

SEM observations were carried out to determine the influence of yttrium ion implantation on the size of the oxide grains. A decrease in oxide grain size due to yttrium ion implantation has recently been observed by Yang et al. [7] for an $\mathrm{Ni}-20 \mathrm{wt} . \% \mathrm{Cr}$ alloy and is often mentioned as an important fac-

\section{TABLE 1}

Ratios of the spinel (311) to the $\mathrm{Cr}_{2} \mathrm{O}_{3}$ (104) reflections

\begin{tabular}{ll}
\hline Specimen & $\begin{array}{l}\text { Ratio of the spinel (311) to } \\
\text { the } \mathrm{Cr}_{2} \mathrm{O}_{3}(104) \text { reflection }\end{array}$ \\
\hline $\begin{array}{l}\text { Unimplanted } \\
\text { Implanted with }\end{array}$ & 1 to 2 \\
$10^{16} \mathrm{Y}^{+} \mathrm{cm}^{-2}$ & 1 to 1
\end{tabular}


tor in the oxidation kinetics of alloys. This decrease is considered to result in a more adherent and less porous oxide scale [8].

SEM observations were made of the grains of the initially formed oxide as well as of the outer oxide of an oxide scale $1.4 \mu \mathrm{m}$ thick. It turned out that there is no significant difference between the oxide grain size for yttriumimplanted samples and that for unimplanted samples. Figure 5 and Fig. 6 show the outer scales for unimplanted pre-oxidized Incoloy $800 \mathrm{H}$ and yttrium-implanted pre-oxidized Incoloy $800 \mathrm{H}$ respectively.

Although no differences in oxide grain size could be observed, important information from SEM observations was obtained. Oxidation of Incoloy $800 \mathrm{H}$ leads to increased corrosion at the grain boundaries of the austenitic alloy. This corrosion on the grain boundaries is much more pronounced for unimplanted

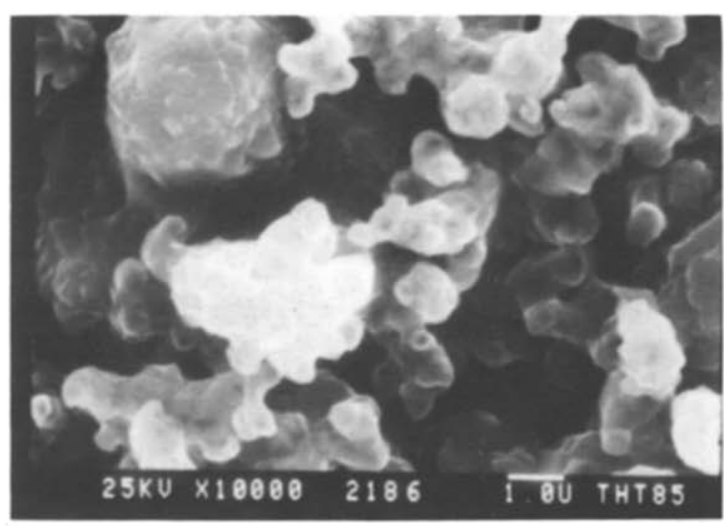

Fig. 5. Outer oxide scale of an unimplanted sample.

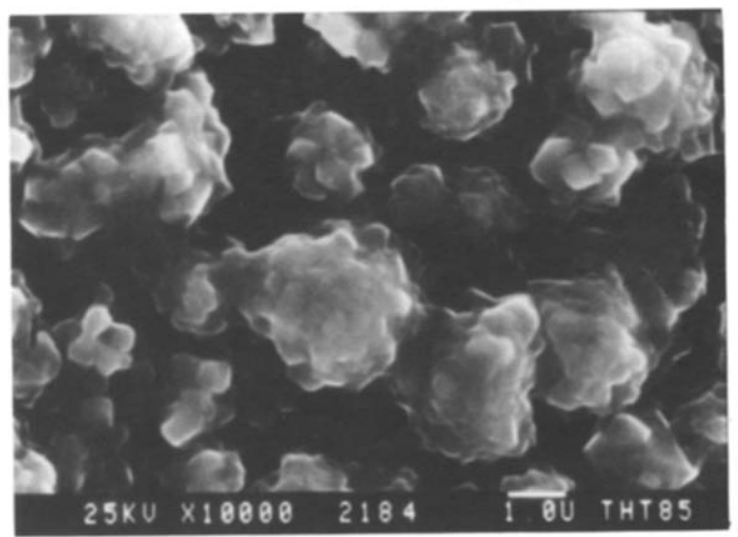

Fig. 6. Outer oxide scale of an yttrium-implanted sample. than for yttrium-implanted samples (Figs. 7 and 8). It was also observed that in yttriumimplanted samples the boundaries indicate that the alloy grain structure is not continuous in contrast with the corresponding situation in unimplanted specimens. Also in unimplanted samples there are more lines indicating the alloy grain structure. No difference between the alloy grain size for implanted alloy and that for unimplanted alloy was observed on an etched cross-section of the samples. For implanted samples, only part of the alloy grain boundaries shows increased oxidation.

\section{DISCUSSION AND CONCLUSIONS}

Yttrium-implanted pre-oxidized Incoloy $800 \mathrm{H}$ samples show better corrosion resist-

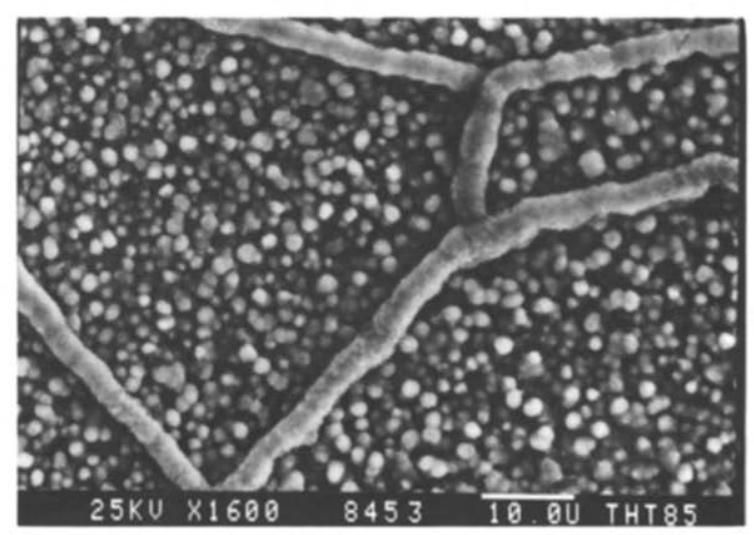

Fig. 7. Oxidized unimplanted sample.

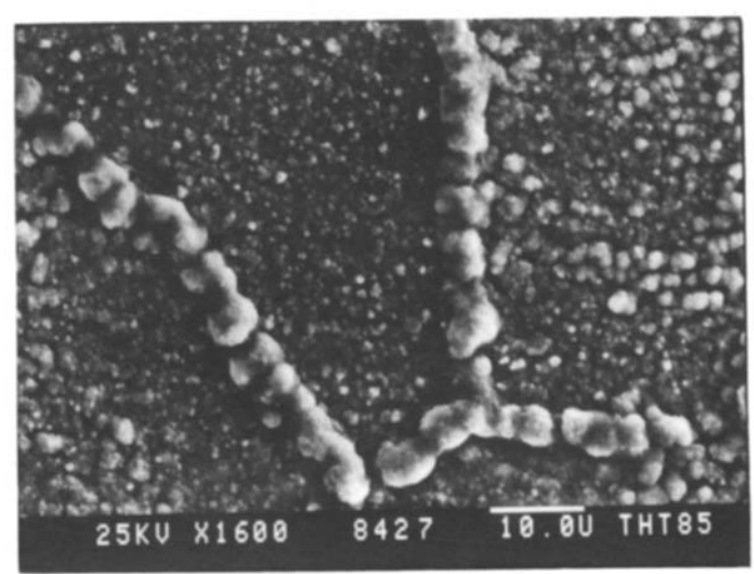

Fig. 8. Oxidized yttrium-implanted sample. 
ance in sulphidizing atmospheres than do unimplanted specimens. Aluminium implantation or krypton implantation of pre-oxidized Incoloy $800 \mathrm{H}$ does not have a beneficial effect on sulphidation. The agreement in sulphidation and oxidation rates for the various implanted elements strongly suggests that the mechanisms leading to an improved corrosion resistance are similar for both processes. Among the several explanations that have been suggested for the improvement in the oxidation resistance of implanted alloys, radiation damage is not very likely since implanted krypton, which should give as much radiation damage as yttrium, turns out to have little or no influence on the oxidation rate of stainless steels [5]. The change in oxidation rate due to yttrium implantation cannot be ascribed to a change in the oxide grain size, since oxidation of unimplanted material results in oxide layers with the same grain structure. Yttrium implantation of Incoloy $800 \mathrm{H}$ was shown to influence the oxide composition. The observed change in composition is probably not the main cause for the observed differences in kinetics because spinels are generally considered to be less protective than $\mathrm{Cr}_{2} \mathrm{O}_{3}$ as a result of a larger derivation from stoichiometry.

SEM observations suggest that the reduction in oxidation kinetics for yttrium-implanted samples may be due to the reduction in alloy grain boundary diffusion. The reduction in sulphidation rate may arise from the same cause since sulphidation also starts at the grain boundaries.

After oxidation the implanted yttrium is present in the oxide and is concentrated at the oxide-gas interface. The reason for this distribution is not fully understood and may be due to a displacement of relatively large $\mathrm{Y}_{2} \mathrm{O}_{3}$ particles by the growing oxide scales. The $\mathrm{Y}_{2} \mathrm{O}_{3}$ particles may indeed be large, in accordance with the results of Bennett et al. $[3,9]$ who recently reported the observation of $\mathrm{Y}_{2} \mathrm{O}_{3}$ particles of $5000 \AA$ or more for an yttrium-implanted $\mathrm{Cr}_{2} \mathrm{O}_{3}$-forming alloy. Young [10] observed a displacement of palladium markers by a growing oxide scale and ascribed this phenomenon to the particle size also.

It cannot be excluded that some yttrium remains in the alloy or near the alloy-oxide interface. It has been observed that, at a certain implanted yttrium dose for $\mathrm{Cr}_{2} \mathrm{O}_{3}$-forming alloys, a further increase in implantation dose does not result in a further improvement of the oxidation resistance [2]. This minimum dose may be effective at the oxide-alloy interface or on the alloy grain boundaries.

\section{ACKNOWLEDGMENTS}

The authors gratefully acknowledge the University of Groningen for providing the implantation and Rutherford backscattering facilities. In particular, thanks are due to J. Smit and Dr. P. J. M. Smulders for their assistance with the experiments.

\section{REFERENCES}

1 M. J. Bennett, G. Dearnaley, M. R. Houlton, R. W. M. Hawes, P. D. Goode and M. A. Wilkins, Corros. Sci., 20 (1980) 73.

2 M. J. Bennett, G. Dearnaley, M. R. Houlton and R. W. M. Hawes, in V. Ashworth, W. A. Grant and R. P. M. Procter (eds.), Proc. Conf. on Ion Implantation into Metals, Pergamon, Oxford, 1982 , p. 264

3 M. J. Bennett, B. A. Bellamy, C. F. Knights, N. Meadows and N. J. Eyre, Mater. Sci. Eng., 69 (1985) 359.

4 J. C. Pivin, C. Roques-Carmes, J. Chaumont and H. Bernas, Corros. Sci., 20 (1980) 947.

5 J. E. Antill, M. J. Bennett, R. F. A. Carney, G. Dearnaley, F. H. Fern, P. D. Goode, B. L. Myatt, J. F. Turner and J. B. Warburton, Corros. Sci., 16 (1976) 729 .

6 J. H. Kort, T. Fransen and P. J. Gellings, Appl. Surf. Sci., 25 (1986) 237.

7 C. H. Yang, G. E. Welschand and T. E. Mitchell, Mater. Sci. Eng., 69 (1985) 351.

8 D. P. Whittle and J. Stringer, Philos. Trans. $R$. Soc. London, Ser, A, 295 (1980) 309.

9 M. J. Bennett, J. A. Desport and P. A. Labun, to be published.

10 E. W. A. Young, Thesis, University of Utrecht, 1986. 